\title{
Perspectivas ideológicas em política externa nas eleições presidenciais brasileiras de 2018*
}

\author{
Ideological Perspectives \\ on Foreign Policy \\ in The 2018 Brazilian Presidential Election
}

Flávio Contrera** y Matheus Lucas Hebling****

RESUMO: 0 artigo teve como objetivo principal estimar o posicionamento e diferenciar ideologicamente os partidos que disputaram as eleições presidenciais brasileiras de 2018, através da análise de suas posições sobre política externa, expressas em seus manifestos de campanha. As posiç̃ões em 2018 foram contrastadas também com os manifestos das campanhas de 2010 e 2014 . Os resultados demonstram que a maioria dos partidos se localizam à direita e que apenas aqueles à extrema-esquerda defendem um papel minimalista para a políitca externa brasileira. A comparação com eleições anteriores mostra estabilidade na ordenação ideológica partidária, e que os cinco partidos que disputaram as últimas três eleições presidenciais se moveram à esquerda.

Palavras-Chave: Eleições; Ideologia; Políitica Externa Brasileira; Partidos Políiticos.

ABSTRACT: The main objective of the article was to estimate the position and ideologically differentiate the parties that disputed the Brazilian presidential elections of 2018, by analyzing their positions on foreign policy, expressed in their campaign manifestos. Positions in 2018 were also contrasted with the 2010 and 2014 campaign manifests. The results show that most parties are on the right and only those on the far left defend a minimalist role for Brazilian foreign policy. Comparison with previous elections shows stability in party ideology, and the five parties that have competed in the last three presidential elections have moved to the left.

KeywordS: Elections; Ideology; Brazilian Foreign Policy; Political Parties.

Recibido: 18 de diciembre de 2019

Aceptado: 26 de agosto de 2020

Lectura y revisión lingüística: Dra. Marisela Colín Rodea. Escuela Nacional de Lenguas, Lingüística y Traducción, UNAM.

** Universidade Estadual Paulista (flavio.contrera@gmail.com).

*** Brazilian Research and Studies Center (matheushebling@gmail.com). 
INTRODUÇÃO

$\mathrm{N}$

o primeiro turno das eleições presidenciais brasileiras de 2018, a candidatura de Geraldo Alckmin (PSDB) expressou no horário gratuito de propaganda eleitoral (HGPE) na TV que o país vivia um dos momentos mais delicados de sua democracia. Associando as candidaturas de Jair Bolsonaro (PSL) e Fernando Haddad (PT) ao chavismo, afirmava-se: "o risco de o Brasil se tornar uma nova Venezuela é real, a partir dos extremismos que estão colocados nessa eleição" (PSDB 2018b). No segundo turno, a campanha de Bolsonaro na TV construiu a narrativa de que teria ocorrido uma ascensão do socialismo na América Latina, destacando o papel-chave do Foro de São Paulo, identificando a instituição como o "grupo liderado por Lula e Fidel Castro" (PSL 2018b). Durante o período eleitoral, menções sobre a crise política, econômica e migratória na Venezuela, bem como seu impacto no Estado de Roraima eram frequentes nos veículos de comunicação.

Com efeito, o interesse dos partidos e dos eleitores pelas questões de política externa atingiram um novo patamar nas eleições de 2018. Assuntos como as relações do Brasil com a Venezuela e o futuro do Programa "Mais Médicos" romperam o escopo do noticiário da mídia e da propaganda dos partidos na TV, penetrando nas rodas de conversa dos eleitores e mostrando que a política externa está muito mais envolvida com a produção de política pública do que o eleitor médio pudesse considerar. Partindo desse cenário, procuramos entender o modo como as questões de política externa foram incorporadas nos manifestos de campanha presidenciais, quais perspectivas ideológicas teriam prevalecido nas eleições de 2018 e se ocorreram mudanças de posicionamento ideológico em relação às eleições anteriores.

Com o intuito de responder a essas questões, o artigo teve como objetivo principal estimar o posicionamento e diferenciar ideologicamente os partidos que disputaram as eleições presidenciais brasileiras de 2018, através da análise de suas posições sobre política externa, expressas em seus manifestos de campanha. Ademais, buscou contrastar as estimações 
ideológicas dos partidos em 2018 com as manifestadas em 2010 e 2014, nas escalas esquerda-direita e minimalista-protagonista.

Nesse sentido, este artigo dialoga com a literatura focada em analisar a política externa brasileira através da perspectiva partidária na arena eleitoral (Almeida 1986; 2006; Oliveira e Onuki 2010; Lopes e Faria 2014). Fundamentais para a compreensão do relacionamento entre partidos, eleições e política externa, esses esforços interpretativos foram somados com o estudo em que realizamos uma análise quantitativa dos manifestos de campanha apresentados pelos partidos que tiveram candidatos à Presidência da República em 2014, utilizando escalas ideológicas (Contrera e Hebling 2017). Acreditamos que essas escalas conseguem dar uma visão mais completa de como a política externa é percebida pelos partidos e tratada durante as eleições.

Dialogamos também neste artigo com os trabalhos produzidos no âmbito do Manifesto Research on Political Representation (MARPOR) para a Europa (Merz et al. 2016; Klingemann et al. 2006; Volkens et al. 2013; 2015; Benoit et al. 2012; Regel 2010) e compartilhamos com o grupo a percepção da necessidade de expansão do escopo de aplicação de seu método para a América Latina (Ares e Volkens 2017). Por outro lado, o artigo aqui proposto contrapõe-se aos trabalhos do MARPOR ao concluir que para a realização desta expansão é necessária a adaptação das categorias de análise e da escala RLLE à realidade histórica e socioeconômica local. Neste ponto, compartilhamos da crítica manifestada nos trabalhos de Tarouco e Madeira (2011; 2013a; 2013b), mas elaboramos categorias próprias para compreender a política externa.

Este artigo está organizado em quatro seções. Na primeira delas apresentamos os dados e discutimos a metodologia empregada. Na segunda iniciamos a apresentação dos resultados, com a discussão das ênfases temáticas em política externa nas eleições presidenciais de 2018. Na terceira seção explicamos as variações nos posicionamentos dos partidos na política externa entre as eleições de 2010 e 2018. Por fim, apresentamos as conclusões do estudo. 


\section{DADOS E MÉTODOS}

Analisamos os manifestos de campanha dos 13 partidos que apresentaram candidatura à Presidência da República Federativa do Brasil em 2018. São eles: o Partido Democrático Trabalhista (PDT), o Partido dos Trabalhadores (PT), o Movimento Democrático Brasileiro (MDB), o Partido Socialista dos Trabalhadores Unificados (PSTU), o Partido Social Liberal (PSL), a Rede Sustentabilidade (REDE), o Podemos (PODE), o Democracia Cristã (DC), o Partido Novo (NOvO), o Partido da Social Democracia Brasileira (PSDB), o Partido Socialismo e Liberdade (PSOL), o Patriota (PATRI) e o Partido Pátria Livre (PPL).

Adicionalmente, comparamos as estimações realizadas nos manifestos das eleições de 2018 com as estimações realizadas nos manifestos das eleições de 2014. Por fim, estimamos e as comparamos também com as posições partidárias nos manifestos das eleições de 2010. Todos os manifestos de campanha analisados estão disponíveis no endereço eletrônico do Tribunal Superior Eleitoral (TSE), e podem ser consultados através da plataforma DivulgaCand.

Para conduzir esta investigação partimos de uma técnica quantitativa, a Análise de Conteúdo. Especificamente, empregamos uma análise temática. O intuito desta análise é quantificar a frequência de categorias construídas, identificadas e classificadas nos textos a partir de um critério semântico. Este procedimento, segundo Bardin (2002) visa elucidar a importância de determinada temática, a qual varia de acordo sua frequência de aparição. Análises de conteúdo categóricas podem partir de diferentes modelos para codificar documentos. Partimos aqui de um modelo misto, isto é, adaptamos e combinamos as categorias do MARPOR com categorias elaboradas por nós. Formado em 1979 com o objetivo de investigar quais eram as questões políticas que dividiam os partidos no Pós-Guerra e se eles eram divergentes ou convergentes em termos políticos e ideológicos, o então Manifesto Research Group (MRG) desenvolveu uma metodologia específica de análise de conteúdo de manifesto partidário, a partir de um quadro composto por 56 categorias temáticas (Klingemann et al. 2006). Tendo em vista nosso intuito de analisar um domínio temático específi- 
Co, a política externa, o quadro analítico do MARPOR nos pareceu limitante. Essa limitação se deve à estreita abrangência temática das categorias presentes no domínio "Relações Exteriores", que exclui temáticas como economia internacional, sustentabilidade e direitos humanos. Para superar essas limitações, classificamos as posições dos partidos políticos em assuntos de política externa nas categorias presentes no Quadro 1.

Para classificar as posições partidárias sobre política externa nos manifestos de campanha seguimos o método do MARPOR. Esse método consiste em identificar as unidades de registro, chamadas de quasi-sentenças, e classificá-las em uma das 14 categorias temáticas presentes no Quadro 1. A frequência das categorias é então calculada percentualmente, em cada manifesto (Klingemann et al. 2006). Apresentamos, a seguir, o resultado da análise.

\section{A POLÍTICA EXTERNA NAS ELEIÇÕES PRESIDENCIAIS DE 2018}

Definida por Sartori (1976) como sendo a distância ideológica entre candidatos, partidos e/ou eleitores, a polarização transforma a distribuição de posições políticas ou posições ideológicas, mudando a dinâmica da competição de centrípeta para centrífuga. No Brasil, a competição partidária entre 1994 e 2014 esteve polarizada entre PSDB e PT, que além de alternarem-se no poder lideraram as principais coligações eleitorais no período, atraindo os demais partidos a gravitar em torno de suas candidaturas presidenciais (Limongi e Cortez 2010; Braga e Pimentel Jr. 2011; Melo e Câmara 2012).

Ainda que não tenhamos como foco neste trabalho realizar um exame minucioso sobre as causas da polarização, vale destacar que várias delas se referem ao momento da eleição ou impactam os programas partidários diretamente. A tomada do país por protestos em 2013 e posteriormente a eleição presidencial de 2014 mostraram além da insatisfação com o estado atual da democracia brasileira e sua responsividade perante as demandas dos eleitores, o quão polarizado o país estava. No ínterim entre 2014 e 2018, essa polarização só cresceria com os inúmeros conflitos políticos e 


\begin{tabular}{|c|c|c|c|c|c|c|c|}
\hline 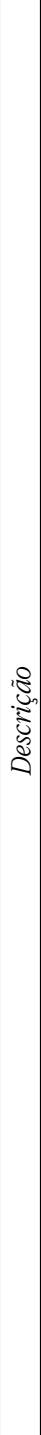 & 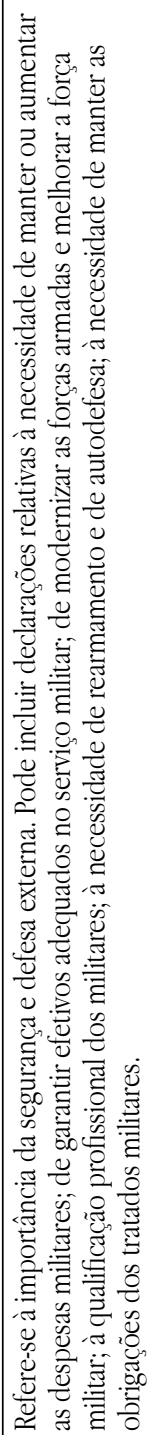 & 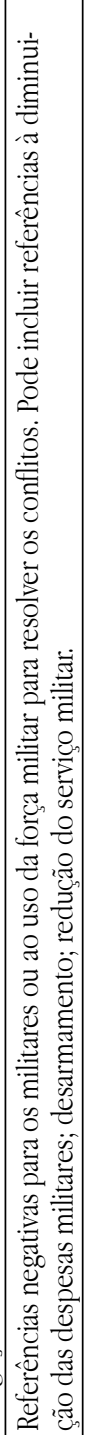 & 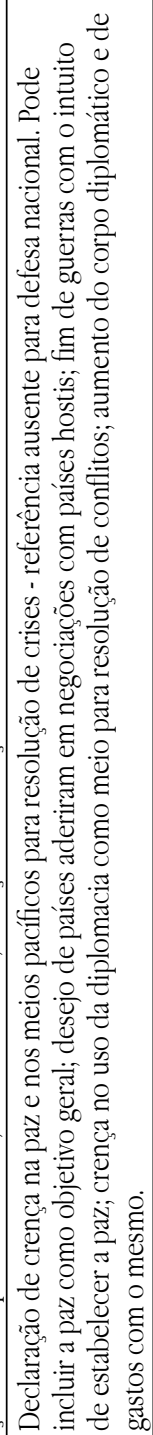 & 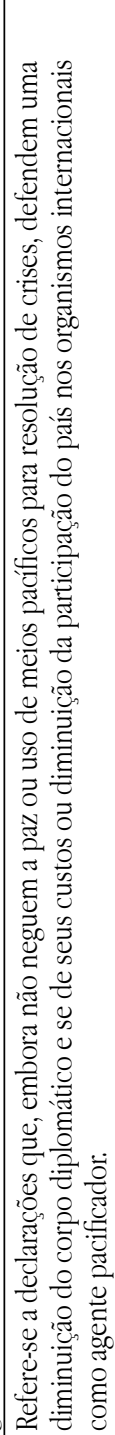 & 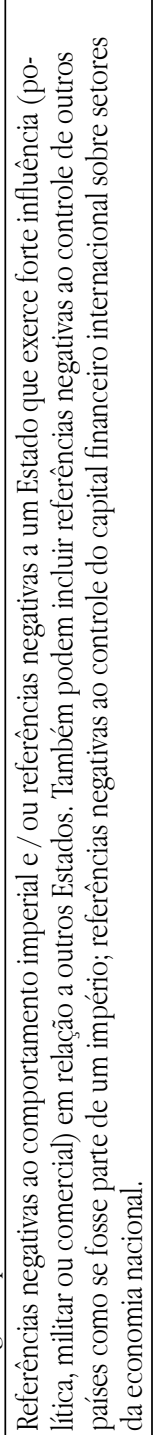 & 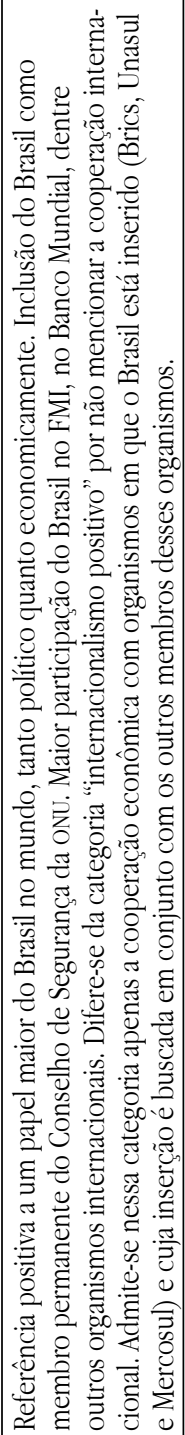 & 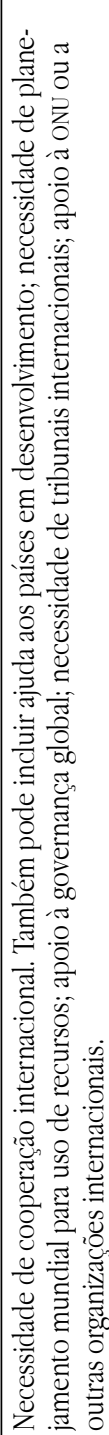 \\
\hline & 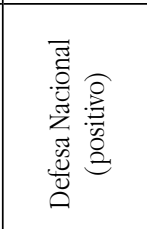 & 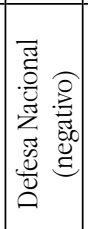 & 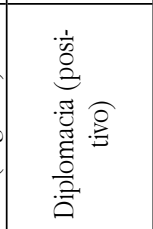 & 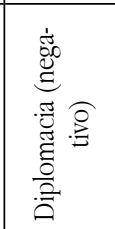 & 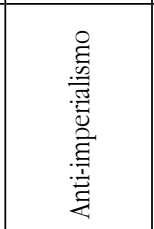 & 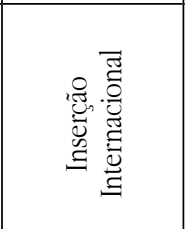 & 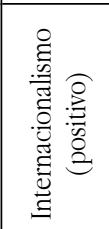 \\
\hline & 会 & 玄 & $\tilde{\Xi}$ & 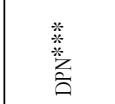 & द & & $\underline{\xi}$ \\
\hline
\end{tabular}




\begin{tabular}{|c|c|c|c|c|c|c|c|}
\hline 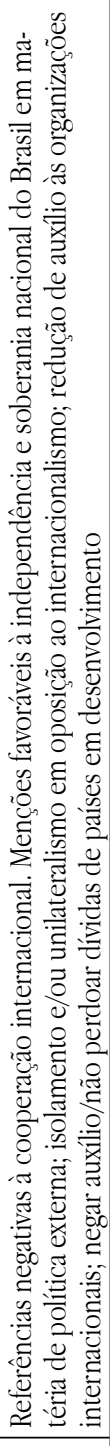 & 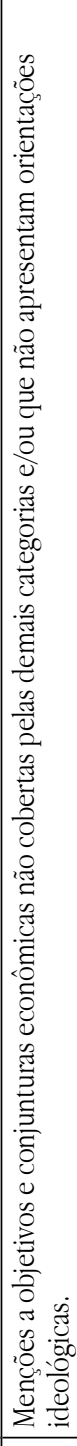 & 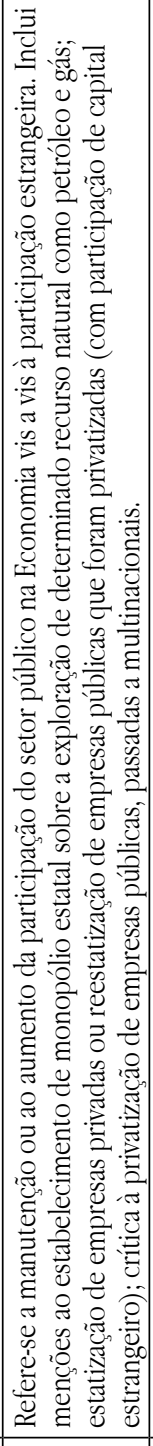 & 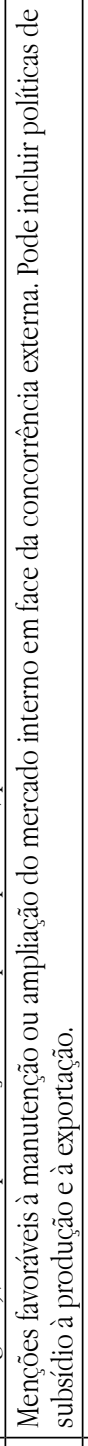 & 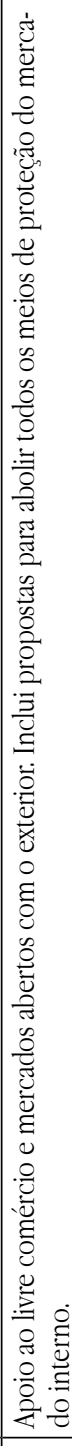 & 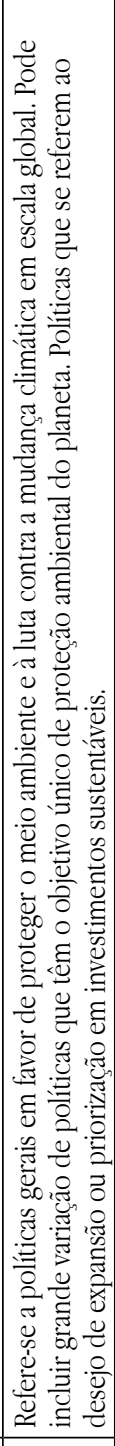 & 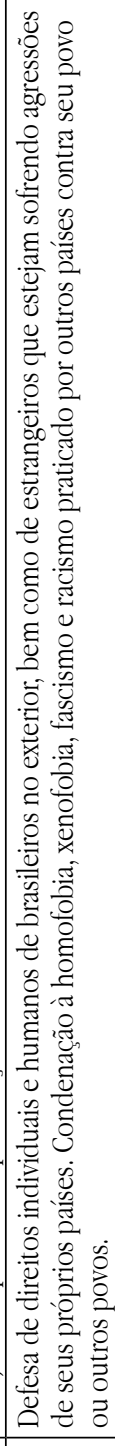 & 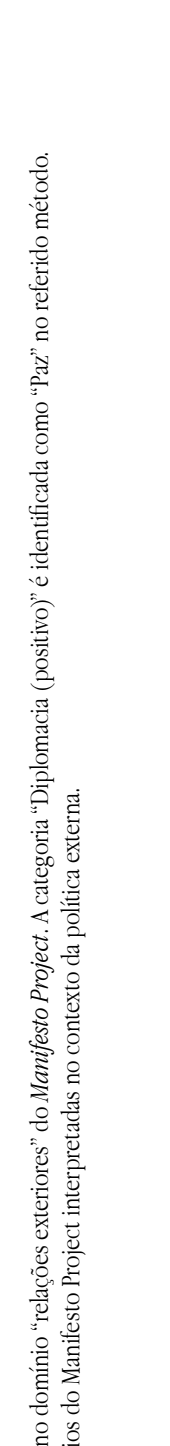 \\
\hline 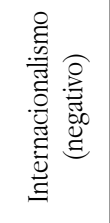 & 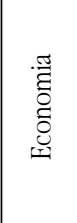 & \pm & 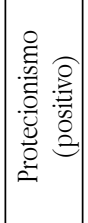 & 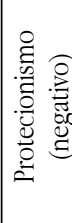 & 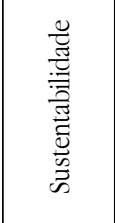 & 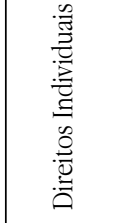 & 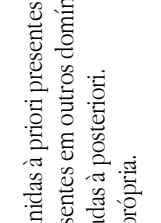 \\
\hline$\Xi$ & 总 & 跑 & & & 20 & 莚 & 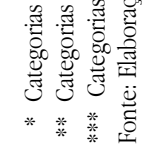 \\
\hline
\end{tabular}


institucionais que foram desde o impeachment da ex-presidente Dilma Rousseff até as acusações de corrupção que culminaram com a prisão do ex-presidente Luiz Inácio Lula da Silva. Em 2018, a polarização entre PT e PSDB fora quebrada pela candidatura de Jair Bolsonaro, pelo PSL, na esteira de um forte crescimento no eleitorado de um sentimento antipartidário, em geral, e antipetista, em particular (Tatagiba 2014; Borges e Vidigal 2018; Telles 2016; Ribeiro et al. 2016).

Embora vista como sendo uma das causas principais de paralisia decisória e instabilidade de governos, nem todo efeito da polarização é negativo. Assim como mostra Lupu (2013), a polarização partidária pode fortalecer os valores e ideais do partido e esclarecer as escolhas dos eleitores, levando à formação de laços mais estreitos entre os eleitores e os partidos. Com efeito, a polarização pode ser dividida em "percebida" e "declarada" (Ascencio e Powell 2016). Enquanto a primeira é medida através de surveys de opinião, a segunda é baseada nas posições que os partidos manifestam em programas de governo. Esses são justamente nosso objeto de análise.

Os manifestos de PSOL (118) e PDT (104) nas eleições presidenciais brasileiras de 2018 foram aqueles em que verificamos maior ênfase em questões de política externa, em números absolutos de unidades de registro. Em seguida vieram, PT (69), REDE (44), PPL (32), PSTU (26), PSL (25), PATRIOTA (20), MDB (19), NOVO (18), PODEMOs (10), PSDB (8) e DC (4). Assim como verificamos na análise dos manifestos das eleições de 2014, em 2018 a maioria dos partidos foi mais propositivo do que analítico na política externa. Também como em 2014, foram exceções a esta característica partidos de esquerda. Apenas 44\% das posições do PSOL e 46,2\% das posições do PSTU foram propositivas. Em lados opostos no espectro ideológico, os dois partidos que chegaram ao segundo turno nas eleições, PSL (24\%) e PT $(17,4 \%)$, foram os que mais expressaram análise de conjuntura positiva na política externa. Em contraste, o partido até então no governo, o MDB, não expressou análise de conjuntura positiva. Os partidos mais propositivos em 2018 foram DC (100\%), MDB (94,7\%) e PODEMOS (90\%). Os dados completos desta análise estão compilados na Tabela 1.

As temáticas mais frequentes nos manifestos foram "Economia" em 10 manifestos, "Internacionalismo (positivo)" em 09 e "Defesa Nacional 
Tabela 1. Classificação das unidades de registros (quasi-sentenças) em proposta ou conjuntura (em \%)

\begin{tabular}{|l|c|c|c|c|c|}
\hline \multicolumn{1}{|c|}{ Partido } & $\begin{array}{c}\text { Conjuntura } \\
\text { Positiva }\end{array}$ & $\begin{array}{c}\text { Conjuntura } \\
\text { Negativa }\end{array}$ & $\begin{array}{c}\text { Conjuntura } \\
\text { Neutra }\end{array}$ & $\begin{array}{c}\text { Proposta } \\
\text { Geral }\end{array}$ & $\begin{array}{c}\text { Proposta } \\
\text { Especifica }\end{array}$ \\
\hline DC & & & & $100 \%$ & \\
\hline MDB & & & $5.3 \%$ & $68.4 \%$ & $26.3 \%$ \\
\hline NOVO & $5.6 \%$ & $27.8 \%$ & $5.6 \%$ & $22.2 \%$ & $38.8 \%$ \\
\hline PATRIOTA & $15 \%$ & $25 \%$ & $5 \%$ & $25 \%$ & $30 \%$ \\
\hline PDT & $4.8 \%$ & $6.7 \%$ & $2.9 \%$ & $39.4 \%$ & $46.1 \%$ \\
\hline PODEMOS & $10 \%$ & & & $30 \%$ & $60 \%$ \\
\hline PPL & $9.4 \%$ & $21.9 \%$ & $3.1 \%$ & $31.2 \%$ & $34.4 \%$ \\
\hline PSDB & $12.5 \%$ & & & $62.5 \%$ & $25 \%$ \\
\hline PSL & $24 \%$ & $16 \%$ & & $52 \%$ & $8 \%$ \\
\hline PSOL & $0.8 \%$ & $53.4 \%$ & $1.7 \%$ & $20.3 \%$ & $23.7 \%$ \\
\hline PSTU & & $53.8 \%$ & & $11.6 \%$ & $34.6 \%$ \\
\hline PT & $17.4 \%$ & $26.1 \%$ & & $31.9 \%$ & $24.6 \%$ \\
\hline REDE & $6.8 \%$ & $9.1 \%$ & & $68.2 \%$ & $15.9 \%$ \\
\hline
\end{tabular}

Fonte: Elaboração própria.

(positivo)" em 08. Entre todos os manifestos, apenas a categoria "Diplomacia (negativo)" não foi codificada. PDT (12), PSOL (11) e PT (10) foram os partidos que cobriram o maior número de temáticas distintas em seus manifestos. Em contrapartida, DC e PSTU se concentraram em apenas três temáticas cada um. A frequência de todas as categorias, por manifesto, está compilada na Tabela 2.

\section{Os posicionamentos partidários nas escalas esquerda-direita e minimalista-protagonista}

Para analisar as posições partidárias nos manifestos das eleições de 2018, em termos de perspectivas ideológicas, agrupamos as temáticas de política externa nas escalas esquerda-direita e minimalista-protagonista. ${ }^{1}$

1 Ambas as escalas esquerda-direita e minimalista-protagonista foram construídas, discutidas e apresentadas em Contrera e Hebling (2017). 


\begin{tabular}{|c|c|c|c|c|c|c|c|c|c|c|c|c|c|}
\hline$\cong$ & & $\mid \begin{array}{l}00 \\
\infty \\
10 \\
-1\end{array}$ & & & $\stackrel{\partial 0}{=}$ & & & 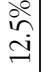 & & $\begin{array}{l}\stackrel{0}{ } \\
\infty \\
\infty\end{array}$ & & 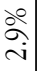 & $\begin{array}{l}\stackrel{0}{0} \\
\underset{\sim}{2}\end{array}$ \\
\hline 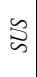 & & $\begin{array}{l}\therefore 0 \\
\stackrel{2}{2} \\
\text { in }\end{array}$ & $\begin{array}{l}\stackrel{0}{0} \\
\text { in }\end{array}$ & & 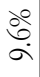 & & & $\begin{array}{l}\text { ஃे } \\
\stackrel{n}{n}\end{array}$ & & 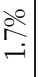 & & $\begin{array}{l}\stackrel{\circ}{\stackrel{\circ}{ \pm}} \\
\stackrel{ \pm}{*}\end{array}$ & $\begin{array}{l}\stackrel{\circ}{ } \\
\stackrel{n}{n}\end{array}$ \\
\hline ঔ & & 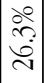 & $\begin{array}{l}\circ \\
\stackrel{\circ}{n}\end{array}$ & & $\stackrel{\partial 0}{\stackrel{\sim}{\sim}}$ & 유 & & 竎 & ఏ̊ర్రి & & & & $\begin{array}{l}\stackrel{\circ}{2} \\
\text { } \\
\end{array}$ \\
\hline ミ্ & & & & 今ి & $\stackrel{\circ}{\sim}$ & 今ి & 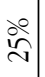 & & $\stackrel{\leftrightarrow}{\rightarrow}$ & $\begin{array}{l}\stackrel{0}{r} \\
\stackrel{-}{r}\end{array}$ & & $\stackrel{\text { }}{\stackrel{2}{r}}$ & \\
\hline 恿 & $\stackrel{20}{\sim}$ & 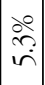 & $\begin{array}{l}\stackrel{\circ}{\mathrm{N}} \\
\underset{\mathrm{d}}{ }\end{array}$ & ồ & & $\stackrel{\circ}{0}$ & $\begin{array}{l}\stackrel{\partial}{\vec{\lambda}} \\
\text { a }\end{array}$ & 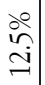 & & $\begin{array}{l}\stackrel{\circ}{+} \\
\stackrel{\sim}{+}\end{array}$ & $\begin{array}{l}\frac{\alpha}{2} \\
\frac{1}{r}\end{array}$ & $\begin{array}{l}\stackrel{\circ}{~} \\
\text { ปे }\end{array}$ & \\
\hline 通 & & & & & $\begin{array}{l}\frac{2}{10} \\
\hat{\sigma}\end{array}$ & & 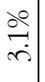 & & & $\begin{array}{l}\stackrel{\circ}{\sim} \\
\stackrel{2}{i}\end{array}$ & 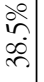 & 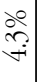 & \\
\hline$\geqq$ & & & & 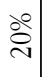 & $\begin{array}{l}\infty \\
\infty \\
\text { ஸे }\end{array}$ & & & & $\stackrel{\leftrightarrow}{+}$ & 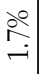 & & & \\
\hline$\Xi$ & $\stackrel{\circ}{\circ}$ & $\stackrel{\circ}{\vec{\sim}}$ & 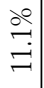 & & 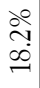 & & $\begin{array}{l}\text { 今̊ } \\
\stackrel{1}{-1}\end{array}$ & & $\stackrel{\circ}{\stackrel{\nu}{2}}$ & 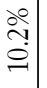 & & $\begin{array}{l}\circ \\
\infty \\
\infty \\
\infty \\
-1\end{array}$ & 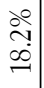 \\
\hline$\stackrel{\xi}{\xi}$ & & & $\begin{array}{l}\stackrel{\circ}{\rightrightarrows} \\
\rightleftharpoons \\
=\end{array}$ & & $\begin{array}{l}\text { } \\
\stackrel{\leftrightarrow}{0}\end{array}$ & & 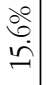 & & & $\begin{array}{l}\stackrel{\circ}{\rightleftarrows} \\
i n\end{array}$ & & 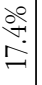 & $\frac{a ̊}{a}$ \\
\hline 艺 & & & & 우 & 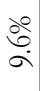 & & 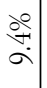 & & & 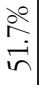 & $\begin{array}{l}\infty \\
\infty \\
\check{n} \\
i\end{array}$ & ঐ̊ & 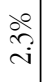 \\
\hline ‡ & & & & & & & & & & & & & \\
\hline ఃิ & ㅇํㅁ & & & & 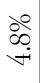 & & & & $\stackrel{\circ}{+}$ & $\stackrel{\circ}{\exists}$ & & $\begin{array}{c}\circ \\
\stackrel{0}{\rightleftarrows} \\
0\end{array}$ & 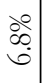 \\
\hline 引 & & & & & $\stackrel{\circ}{\sim}$ & & & & & $\begin{array}{l}\stackrel{2}{\sim} \\
\text { in }\end{array}$ & & & \\
\hline$\stackrel{\vdots}{\vdots}$ & & 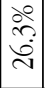 & & $\begin{array}{l}\stackrel{\circ}{\vartheta} \\
\stackrel{0}{*}\end{array}$ & $\begin{array}{l}\text { o̊ } \\
\infty \\
\text { ஸे }\end{array}$ & ळे & $\begin{array}{l}\stackrel{\circ}{a} \\
\stackrel{+}{a}\end{array}$ & & $\begin{array}{l}\stackrel{\circ}{\sim} \\
\stackrel{1}{n}\end{array}$ & & & $\begin{array}{l}\stackrel{\circ}{i} \\
\stackrel{ \pm}{ \pm}\end{array}$ & $\frac{\partial \circ}{a ̆}$ \\
\hline 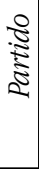 & $\breve{a}$ & 悹 & $\begin{array}{l}0 \\
0 \\
z\end{array}$ & 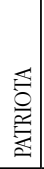 & 官 & $\begin{array}{l}2 \\
0 \\
\sum_{1=1} \\
0 \\
0 \\
0\end{array}$ & $\vec{\Xi}$ & 悹 & $\overrightarrow{\mathscr{L}}$ & $\begin{array}{l}\overrightarrow{0} \\
0\end{array}$ & $\begin{array}{l}\overrightarrow{2} \\
2 \\
2\end{array}$ & 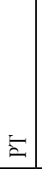 & 斵 \\
\hline
\end{tabular}


Representam perspectivas de esquerda as categorias "Estatização", "Antiimperialismo", "Protecionismo (positivo)" e "Defesa Nacional (negativo)". Por outro lado, representam perspectivas de direita as categorias "Protecionismo (negativo)" e "Defesa Nacional (positivo)". Desse modo, se por um lado a escala esquerda-direita na política externa tem como foco contrapor perspectivas sobre o grau de intervenção estatal na economia, por outro, tem como objetivo diferenciar perspectivas sobre o escopo e atuação das forças armadas.

Após efetuar a soma das frequências das categorias de esquerda e direita foi realizada uma subtração entre as duas somas, conforme a fórmula aplicada pelo MARPOR. Resultados positivos indicam posições à direita, enquanto que resultados negativos indicam posições à esquerda. A escala varia de -100 à +100 , sendo esses considerados os pontos extremos à esquerda e à direita, respectivamente.

Os resultados das estimações apontaram os posicionamentos do PSTU à extrema-esquerda, do PSOL e do PPL à esquerda, do PT à centro-esquerda, do PATRIOTA e do DC ao centro, do PDT e do PSDB à centro-direita, e da REDE, NOVO, MDB, PSL e PODEMOS à direita. Em grande medida, os posicionamentos dos partidos na escala esquerda-direita na política externa nas eleições de 2018 são condizentes com os posicionamentos ideológicos atribuídos aos partidos por especialistas, quando analisam as posições dos partidos sobre as políticas públicas em geral (Madeira e Tarouco 2012; Silva et al. 2013; Maciel et al. 2017). São exceções os manifestos de PDT, REDE e MDB, posicionados mais à direita na política externa que os manifestos de PATRIOTA e DC, os quais são recorrentemente classificados por especialistas à direita. Essas tendências podem ser observadas no Gráfico I.

Para verificar a posição dos partidos quanto ao escopo e à atuação do Brasil no exterior, calculamos também a posição dos partidos na escala minimalista-protagonista. Uma posição minimalista é representada por posições partidárias classificadas nas categorias "Anti-imperialismo", "Defesa Nacional (negativo)", "Internacionalismo (negativo)" e "Diplomacia (negativo)". Por outro lado, uma posição protagonista é tipificada por posições partidárias classificadas nas categorias "Inserção Internacional", "Defesa Nacional (positivo)", "Internacionalismo (positivo)" e "Diplomacia (posi- 
Gráfico I. Posições dos partidos que disputaram as eleições de 2018 na escala esquerda-direita da política externa

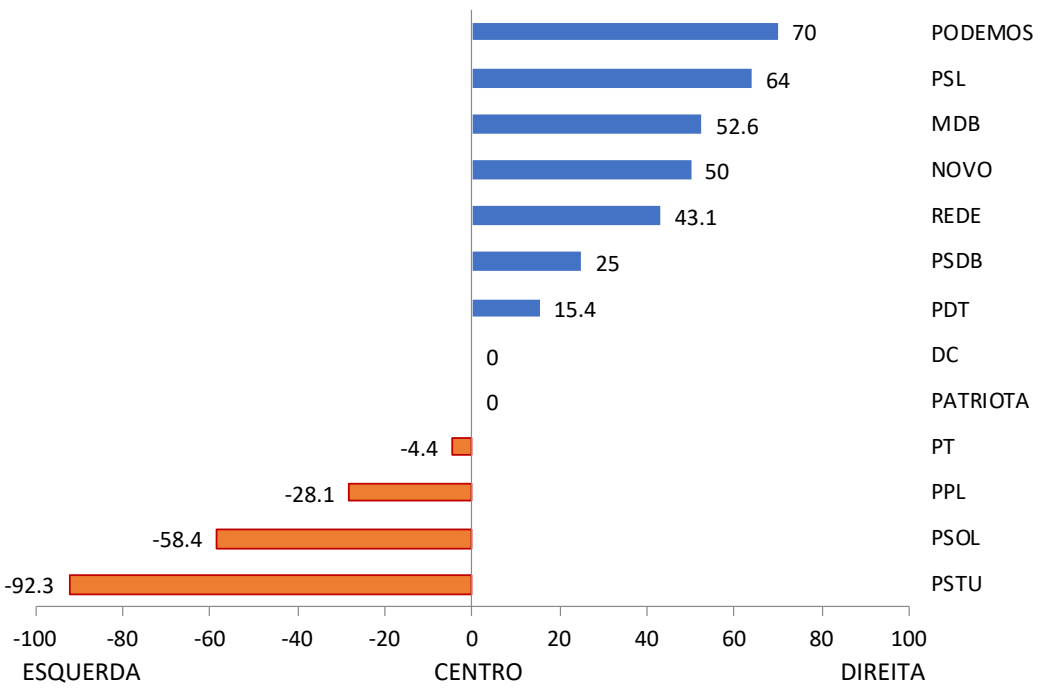

Fonte: Elaboração própria.

tivo)". Desse modo, essa escala tem como objetivo analisar se perspectivas internacionalistas, que ao mesmo tempo, buscam a expansão do papel do Brasil em organizações e no sistema internacional e o fortalecimento da defesa e da segurança nacional, são percebidas pelos partidos como busca de protagonismo internacional ou, contrariamente, se são percebidas pelos partidos como exercício de imperialismo.

Os resultados das estimações apontaram o PSTU, o PSOL e o PATRIOTA posicionados no espectro minimalista da escala. No espectro protagonista estão posicionados NOVO, PODEMOS, PPL, REDE, MDB, PDT, PT, PSL e DC. O manifesto do PSDB não apresentou posições em quaisquer das categorias desta escala e, portanto, não pode ser posicionado. Estas posições podem ser verificadas no Gráfico II.

Comparando as estimações da escala esquerda-direita com as estimações da escala minimalista-protagonista podemos perceber que os partidos mais próximos à extrema-esquerda são também os partidos posicionados 
Gráfico II. Posições dos partidos que disputaram as eleições presidenciais de 2018 na escala minimalista-protagonista

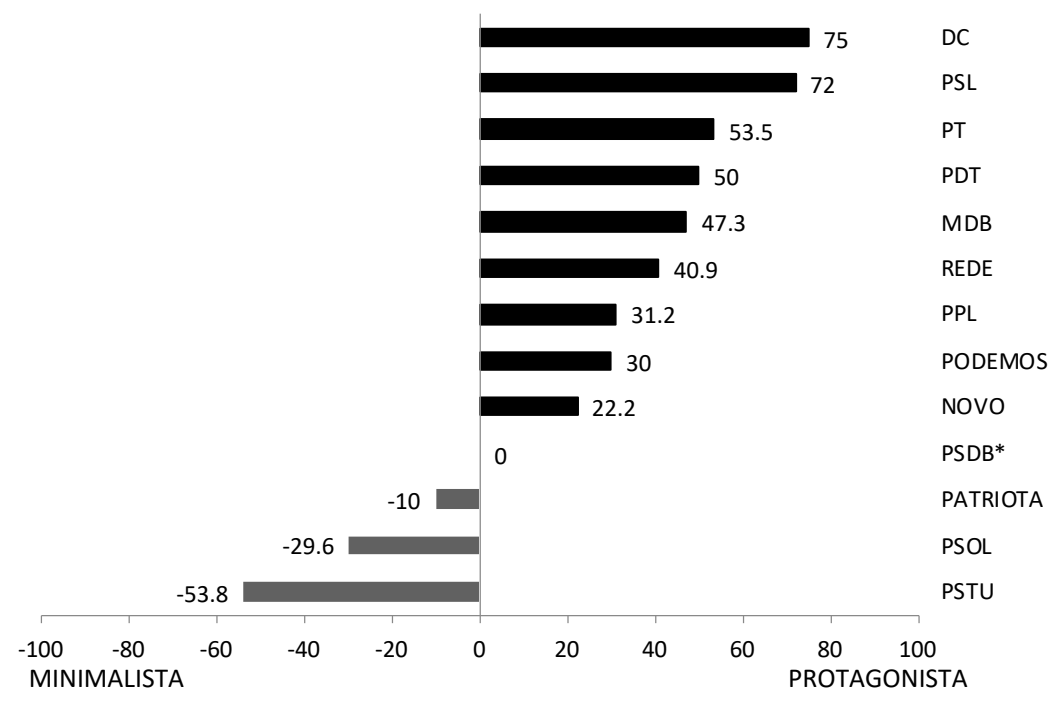

Fonte: Elaboração própria.

como minimalistas. De outro modo, partidos de centro-esquerda aparecem posicionados como protagonistas. Isso se deve à concepção distinta que os partidos de centro-esquerda apresentam em relação às forças armadas, associada à defesa da soberania e ao ativismo na política externa. Em contrapartida, os partidos à extrema-esquerda tendem a se posicionar contrariamente a posições que poderiam ser interpretadas como imperialistas, como o emprego de tropas brasileiras no exterior, por exemplo. Por conta destas distintas concepções o PT apareceu mais próximo de seu principal adversário na eleição de 2018, o PSL, do que de PSOL e PSTU. O mesmo se aplica a PPL e PDT, que se distanciam dos partidos de extrema-esquerda em posições sobre o protagonismo do Brasil no exterior. Apresentamos a seguir um panorama geral das posições manifestadas pelos partidos nas temáticas de política externa. As categorias foram agrupadas nas seguintes temáticas: intervenção estatal na economia e livre-mercado; diplomacia, direitos humanos e internacionalismo; segurança e poder; e sustentabilidade. 


\section{Intervenção estatal na economia e livre-mercado}

Do ponto de vista teórico, a disputa entre os defensores de intervenção estatal na economia e os propaladores da ideia de livre-mercado não se restringe ao debate desenvolvido no século XX envolvendo os teóricos do welfare economics (Keynes 1936) e do neoliberalismo (Hayek 1944; Friedman 1962; Buchanan e Tullock 1965). Antes disso, a disputa de ideias se travou entre Friedrich List (1841), cuja defesa do protecionismo estava assentada na teoria econômica mercantilista, e Adam Smith (1966) e David Ricardo (1817), cujas obras estão assentadas na doutrina do livre-comércio da teoria do comércio internacional.

Expressa na categoria "Protecionismo: negativo", a defesa do livre-comércio e de maior abertura comercial foi manifestada por PODEMOS, PSL, MDB, NOVO, REDE, PSDB e PDT. Entre as propostas mais abordadas pelos partidos está a negociação de novos acordos de livre-comércio (Podemos, MDB, NOVO, REDE e PSDB), o aprofundamento do livre-comércio dentro do Mercosul (MDB, REDE e PDT), a conclusão das negociações com a União Europeia (MDB e REDE), a busca de um acordo de livre-comércio com a Aliança do Pacífico (REDE), e a redução de tarifas de importação (PODEMOS, PSL, REDE e PDT). Especificamente, o NOVO propôs ainda a eliminação das exigências de conteúdo local e revogação das referências na legislação comercial por "similar nacional", a internacionalização das empresas brasileiras com a remoção de barreiras ao investimento no exterior e o fim da indução privilegiada de "campeões nacionais".

Em contrapartida, a defesa de medidas protecionistas na economia está presente em partidos de todos os matizes ideológicos, da esquerda à direita. A esse respeito, o PODEMos propôs a defesa do produto nacional pela isonomia econômica. O PSL salientou a necessidade de não celebrar acordos comerciais espúrios, sobretudo com "ditadores internacionais". O PATRIOTA, por sua vez, propôs fortalecer a competitividade das commodities brasileiras no mercado internacional. Já o PDT defendeu em seu manifesto o desenvolvimento de mecanismos que facilitassem o acesso dos exportadores a financiamentos com custos compatíveis aos obtidos por seus concorrentes externos. PT e PPL defenderam a criação de um imposto 
regulatório sobre a exportação. PSOL e PT manifestaram ainda preocupação com a volatilidade da taxa de câmbio.

Ainda que a ideia de estatização seja amplamente associada à esquerda, ela nada tem a ver com socialismo, tendo existido em regimes não socialistas e até mesmo em regimes antissocialistas (Hastings et al. 2000). Por outro lado, cabe destacar que a estatização foi um dos principais mecanismos defendidos por social-democratas e socialistas reformistas, visando a transição gradual para o socialismo. Mais pela experiência histórica que pela teoria, a estatização tem sido defendida principalmente por partidos de esquerda.

A defesa da estatização ou reestatização de empresas públicas que foram privatizadas ou concedidas à exploração por empresas privadas de capital estrangeiro aparece como proposta nos manifestos de partidos identificados historicamente no campo da esquerda. Eles são PSTU, PSOL, PPL, PT e PDT. Com o intuito de resguardar a soberania nacional, sobretudo em relação ao setor energético, consta nos manifestos de PSTU, PSOL, PT e PDT a defesa da Petrobrás e a recuperação dos campos do Pré-Sal vendidos pelo Governo Temer. A defesa do controle nacional do sistema hídrico foi manifestada por PSOL, PDT e PT. A retomada do controle da EMBRAER foi proposta por PSTU, PSOL, PPL, PT e PDT. Especificamente, o PSTU defendeu a reestatização da VALE e o PDT o controle nacional sobre a Eletrobrás.

Finalmente, o anti-imperialismo econômico está associado à teoria de Lenin (2010) sobre a fase monopolista do capitalismo e foi manifestado pelo PSTU, PSOL, PPL, PT, PDT e PATRIOTA. Considerando que a economia brasileira é controlada por grandes empresas multinacionais, sob controle do capital estrangeiro, que se aproveitam de subsídios e isenções e de que a dívida externa constitui um dos principais mecanismos de subordinação do Brasil aos países ricos, seus bancos e empresas, o PSTU propôs a suspensão do pagamento da dívida externa. Assim como o PPL, O PSTU avaliou que o modelo do agronegócio brasileiro beneficia o capital financeiro internacional, sendo a principal expressão da desnacionalização da economia brasileira. O PSOL, por sua vez, avaliou que o governo Temer estava integrando o país às normas de reprodução do capital no plano internacional, "impondo uma política de desmonte institucional e pro- 
movendo a rapina das empresas estatais pelo capital internacional". Desse modo, o partido entende que o "golpe" (referência ao processo de $\mathrm{im}$ peachment de Dilma Rousseff) teria servido para mudar as relações entre capital e trabalho através das tentativas de privatização da Eletrobrás e do Aquífero Guarani, do aumento de participação de empresas estrangeiras em setores estratégicos para o país e de alterações na lei de mineração.

O PT produziu análise semelhante, manifestando que a resposta dos países centrais no plano externo foi aprofundar as agressões imperialistas contra a soberania nacional dos países economicamente mais frágeis e desencadear as guerras de pilhagem contra alguns países, especialmente os detentores de importantes reservas de petróleo. O PDT propôs o desenvolvimento de uma agenda de reforma da ordem monetária global que criasse condições para ultrapassar o dólar como moeda-reserva do mundo. Ainda que seja classificado por especialistas como um partido de direita, o PATRIOTA salientou que as empresas estatais estratégicas seriam modernizadas e não privatizadas e entregues às grandes corporações internacionais. Finalmente, preocupações com a China foram manifestadas por PDT e PSOL. O PDT destacou a inadmissibilidade de um processo de endividamento com a China que acabasse por comprometer a soberania do Brasil. Já O PSOL avaliou que a mudança qualitativa na entrada do capital chinês no Brasil se refletia na escala e velocidade, mas também na forma financeirizada deste processo, que torna mais difícil conhecer o destino dos investimentos.

Em grande medida as posições manifestadas pelos partidos estão alinhadas com as ideologias em que são recorrentemente classificados por especialistas. São casos desviantes a REDE e o PDT na defesa do livre-comércio e o PATRIOTA na defesa do anti-imperialismo econômico. Não obstante, essas posições empurram REDE e PDT à direita e o PATRIOTA à esquerda na política externa, conforme o Gráfico I.

\section{Diplomacia, direitos humanos e internacionalismo}

Diplomacia, direitos humanos e internacionalismo são temáticas imbricadas nas perspectivas teóricas liberais presentes nas relações internacionais. 
Kant (2003), por exemplo, acreditava que os Estados se aproximariam por interesse por perceberem que a paz é vantajosa, enquanto a guerra é irracional. Destacando os efeitos pacíficos do direito e a ideia de que uma ordem pacífica poderia ser criada apenas por um direito cosmopolita, Kant vislumbrava um pacto internacional entre as repúblicas da qual resultaria uma federação de povos livres. Limitando-se às condições de uma hospitalidade universal, o direito cosmopolita de Kant orientou a política de direitos humanos das Nações Unidas. Por outro lado, perspectivas unilaterais, isolacionistas e nacionalistas não podem ser completamente identificadas com o realismo. Para Rathbun (2008), essas perspectivas estão alinhadas com ideias egoístas associadas à direita.

Quanto à estrutura da diplomacia brasileira, o PSL apontou que o Itamaraty precisa estar a serviço dos valores associados ao povo brasileiro. Já PT, PDT e PSOL destacaram a necessidade de reformar o Itamaraty. Especificamente, o PT assinalou a necessidade de seu fortalecimento, ante o desprestígio e sucateamento. O PDT, por sua vez, propôs a valorização do serviço diplomático, para assegurar aos diplomatas "os instrumentos e as condições de que precisam para atuar em prol do Brasil”. Por fim, o PSOL destacou a necessidade de democratização da política externa com a diversificação do quadro de servidores do Itamaraty. Identificando o Itamaraty como uma "estrutura elitista, corporativista e isolada da população", o PSOL defendeu que mulheres e negros ocupassem mais cargos e tivessem acesso aos cargos mais importantes no serviço diplomático.

Quanto ao papel da diplomacia, o PSOL apontou a necessidade de o Brasil pedir perdão aos paraguaios pelo massacre da Guerra da Tríplice Aliança e propôs a cooperação da diplomacia brasileira com os países fabricantes de armas e munições visando seus controles. Ademais, a promoção da paz mundial esteve presente nos manifestos de DC, PT e REDE. No que diz respeito ao campo dos direitos individuais, MDB, PSDB, PDT, PT e REDE defenderam uma política externa orientada para a defesa da democracia e dos direitos humanos. Já o PSOL, além da defesa dos direitos humanos, destacou a defesa do princípio de solidariedade entre os povos, a proteção aos refugiados e a luta contra todas as formas de opressão no exterior. 
Além de expressar posições que objetivam a cooperação internacional em temáticas como o comércio e a segurança, a análise da categoria "Internacionalismo (positivo)" revela o alinhamento estratégico internacional prioritário aos partidos em termos de parcerias com países do norte e do sul. Nesse sentido, podemos dividir os manifestos analisados em três grupos. No primeiro grupo encontram-se os partidos que manifestaram prioridade às relações Sul-Sul. Eles são o PSOL, PPL e PT. No segundo grupo encontram-se os partidos que apesar de enfatizarem as relações com o Sul, manifestaram a necessidade de fortalecimento das relações com países do Norte. Neste grupo estão PDT, REDE e MDB. Finalmente, está alocado no terceiro grupo o PSL, partido que manifestou prioridade em estabelecer relações bilaterais vis-à-vis às multilaterais e elencou como parceiros somente países do Norte.

No âmbito do fortalecimento das relações Sul-Sul, PSOL, PPL e PT falaram em retomar, enquanto o PDT falou em reanimar, o processo de integração sul-americana. Para tal, o PSOL propôs reestruturar e atualizar organismos multilaterais como o Mercado Comum do Sul (Mercosul), a União de Nações Sul-Americanas (UNASUL), a Comunidade de Estados Latino-Americanos e Caribenhos (CELAC) e o Conselho de Defesa Sul-americano. Este último também fora citado pelo PT. Já o PDT focou na integração das cadeias produtivas na América do Sul, dentro e fora do Mercosul. Em relação à Ásia e à África, o PSOL propôs o estabelecimento de parcerias para além das relações comerciais. A mesma orientação moveu o PT, que propôs retomar a cooperação com os africanos na saúde, educação, segurança alimentar e nutricional. Já a REDE propôs criar um ambiente favorável para que empresas brasileiras participassem do processo de transformação produtiva e do desenvolvimento sustentável da África. O PPL, por sua vez, defendeu o fortalecimento das relações com a África. O PDT propôs a reconstrução das relações do Brasil com a China e com a África. No âmbito das organizações multilaterais, o PSOL propôs a retomada da priorização do IBAS, enquanto que o PPL defendeu a consolidação dos BRICS.

Por outro lado, o fortalecimento das relações com o norte ganhou relevo nos manifestos de MDB, PDT e PSL. A este respeito, o MDB propôs negociar a adesão do Brasil à Organização para a Cooperação e Desen- 
volvimento Econômico (OCDE). Já o PDT propôs fortalecer as relações do Brasil com os EUA, através de parcerias capacitadoras entre as empresas dos dois países e do aprofundamento do comércio bilateral. O PSL (2018a: 79), por seu turno, propôs que o Brasil deixasse de "desprezar ou mesmo atacar democracias importantes como EuA, Israel e Itália”, pois estes países teriam muito a oferecer ao Brasil "em termos de comércio, ciência, tecnologia, inovação, educação e cultura".

No âmbito das temáticas específicas, DC, MDB e PPL propuseram iniciativas de cooperação na área da segurança. Especificamente, o DC propôs estabelecer intercâmbio internacional permanente com Administrações Nacionais na área de segurança pública. Já o MDB, propôs que o Brasil trabalhasse tanto com parceiros tradicionais quanto com parceiros novos, como os BRICS, para ampliar os projetos de cooperação na área de segurança. O PPL, por fim, falou em garantir a participação do Brasil nos grandes experimentos internacionais ligados ao setor nuclear.

Ademais, partidos de todos os matizes ideológicos defenderam a integração do Brasil com as cadeias globais de valor. A este respeito, o NOVO propôs um Brasil integrado com o comércio mundial e com os sistemas de produção. O PSL defendeu facilitar o comércio com países que possam agregar valor econômico e tecnológico ao Brasil. Para o PDT, esta integração viria através de uma reforma da ordem mundial de comércio, para que esta deixasse de ser excludente de parcerias estratégicas entre governos e empresas e de regimes alternativos de propriedade intelectual. O PT, por sua vez, propôs promover a integração das cadeias produtivas regionais, o desenvolvimento da infraestrutura e o fortalecimento de instrumentos de financiamento do desenvolvimento, como o Fundo para a Convergência Estrutural do Mercosul (FOCEM) e o Banco do Sul. Já a REDE defendeu promover o aumento da interdependência econômica, tecnológica, política e cultural com a América do Sul, América do Norte, União Europeia e Leste Asiático.

Finalmente, vale destacar outras iniciativas que perpassam o internacionalismo, tais como a defesa, pelo DC, de uma ordem social mundial baseada em princípios compartilhados; a proposta do NOVO de atração de talentos estrangeiros através da redução da burocracia para a revalidação 
de diplomas; e a proposta do PDT de implantação das convenções 100, 101 e 169 da Organização Internacional do Trabalho (OIT), referentes à discriminação em matéria de emprego, salário e profissão.

Em contrapartida, posições negativas ao internacionalismo foram manifestadas por PSL, PATRIOTA, PDT e PSOL. O PSL destacou que seu governo deixaria "de louvar ditaduras assassinas", em uma possível referência à relação dos Governos petistas (2003-2016) com Cuba e Venezuela. Por suas vezes, PATRIOTA, PDT e PSOL defenderam o princípio da soberania nacional. Para o PATRIOTA, o Brasil necessitava recuperar sua noção de soberania, enfraquecida pela falta de estadistas nacionalistas que defendem as riquezas do país. Já o PDT defendeu a criação de um projeto de construção da soberania nacional. Na visão do partido, o Brasil poderia ser parceiro sem ser protetorado dos Estados Unidos, para ganhar independência em tecnologias de comunicação e defesa. Por fim, o PSOL, além de se comprometer com a defesa da soberania e da autonomia, manifestou franca oposição a acordos com a OCDE.

Segurança e poder: O papel das forças armadas e a atuação do Brasil no exterior

Uma vez que política externa compete pelo mesmo orçamento que a doméstica, é mister que o tópico de segurança seja relevante dentro de diferentes posições no espectro ideológico. Por um lado, dado que partidos políticos possuem valores centrais compartilhados por suas posições domésticas e externas, ideias como liberdade e igualdade são geralmente replicadas em ambos os planos. Dessa forma, como mostra Rathbun (2004), partidos que enfatizam igualdade preocupam-se com as minorias e os menos favorecidos e, portanto, favorecem o estado de bem-estar social, bem como as intervenções em nome das minorias e dos mais desfavorecidos no exterior. Em consonância com esse entendimento, Koch e Sullivan (2010) mostram que partidos que promovem um estado de bem-estar social mais amplo tendem a se opor a grandes exércitos e, portanto, custos altos em defesa. Por um outro lado, partidos políticos podem pos- 
suir políticas externas que diferem daquelas defendidas no âmbito doméstico. Enquanto alguns partidos acreditam no que Jervis (1976) chama de modelo de dissuasão da política internacional, ou seja, que interesses são mais bem guardados pela força e determinação militares, enquanto outros concordam com o que ele chamou de modelo espiral, ou seja, a empatia e a sensibilidade do dilema de segurança.

A busca de inserção internacional do Brasil no exterior foi manifestada por PSOL, PPL, PT, PDT, REDE e NOVO. A esse respeito, a busca por protagonismo e por um lugar no Conselho de Segurança da Organização das Nações Unidas (ONU) foi almejada por REDE e PT, sendo que este último defendeu a reforma da instituição. PSOL, PDT e PT propuseram o fortalecimento dos BRICS. PDT e PT destacaram também a importância de fortalecimento do IBAS. PT e PSOL manifestaram a intenção do Brasil voltar a liderar o Sistema Internacional de Direitos Humanos. Como forma de garantir uma inserção internacional soberana, PSOL e PDT propuseram, o fortalecimento de empresas públicas como Petrobrás e Eletrobrás e o fomento ao setor produtivo, com especial destaque para a indústria manufatureira de alta tecnologia, respectivamente.

Especificamente, o PPL propôs a retomada da política externa independente de João Goulart para fortalecer o desenvolvimento nacional. Visão semelhante foi manifestada pelo PDT, que destacou que a política exterior deve servir nossos interesses e valores, possibilitando ampliar, através de um projeto nacional de desenvolvimento, nosso espaço nas negociações políticas e comerciais globais. A REDE avaliou que a política externa brasileira deveria ser ao mesmo tempo realista e transformadora, para identificar como modular as influências externas no benefício do país e como e quando projetar nossos interesses e influências para o aperfeiçoamento da sociedade internacional. O Novo, por sua vez, propôs um Brasil mais inserido no mundo, orientando sua política externa à maior integração internacional e pautada exclusivamente pelos interesses do país. O PT, finalmente, destacou que sua política externa ativa e altiva abriu novos mercados e parcerias estratégicas com países em desenvolvimento e promoveu a expansão dos interesses nacionais em áreas geográficas antes praticamente abandonadas pela diplomacia do período neoliberal, como 
Oriente Médio, África e o sul da Ásia e propôs a retomada de uma atitude proativa no plano internacional, que passasse pela integração regional como base de inserção do país no mundo.

A defesa do fortalecimento das Forças Armadas uniu partidos desde a centro-esquerda até a direita, estando presente dos manifestos de PPL, PT, PDT, MDB, REDE, PATRIOTA, PODEMOS e PSL. Entre as medidas propostas para seu fortalecimento destacamos o aumento de investimentos para gastos com defesa (PT, PDT; PATRIOTA), proteção e patrulhamento das fronteiras (MDB, PDT, PODEMOS, PATRIOTA, PSL e REDE), reorganização do complexo industrial de defesa (PDT, PT e PPL), a defesa do território amazônico e de nossos recursos naturais (MDB, PODEMOS, PPL), atenção com a segurança cibernética (MDB, PDT, PSL), recomposição e modernização dos equipamentos das Forças Armadas (PDT, PODEMOS e PSL), com aumento de sua qualificação tecnológica (PDT e PSL), recomposição e valorização do efetivo das Forças Armadas e de suas condições de trabalho (PT, REDE, PATRIOTA, PSL).

Especificamente, o PT avaliou negativamente o desvirtuamento que as Forças Armadas têm sofrido em torno do cumprimento do seu papel constitucional de resguardar a nossa soberania. Para que o Brasil recupere sua soberania plena, o PATRIOTA sugere a união entre civis e militares. O apoio da sociedade civil é também destacado no manifesto da REDE, a respeito da atuação das forças armadas, que deverá ser fortalecida para cumprir sua missão constitucional de defesa da pátria. O PDT, por sua vez, destacou seu compromisso com a Estratégia Nacional de Defesa. E o PSL prometeu expandir os colégios militares para todas as capitais do país.

Por outro lado, a redução ou restrição do papel das Forças Armadas aparecem nos manifestos de PDT e PSOL. O PDT destacou que o emprego do Exército em operações internas deve ser sempre excepcional e suplementar, com prioridade para a defesa das fronteiras. O PSOL propôs três eixos de ação: 1) afastar as Forças Armadas de atividades policiais e desmilitarizar as Polícias; 2) subordinar, claramente, as Forças Armadas ao Poder Civil; 3) e manter as Forças Armadas mais como um instrumento dissuasório e de autodefesa do que uma máquina com objetivos belicistas.

PSOL, PPL, PT, PDT e REDE manifestam também posições contrárias ao imperialismo militar e em defesa da autodeterminação dos povos. Con- 
trariamente ao imperialismo brasileiro, o PDT destacou que cabe ao Brasil ascender sem imperar, rejeitando a busca de protagonismo, prestígio e gestos de hegemonia, enquanto exerce sua liderança natural na América do Sul. O PSOL, por sua vez, criticou a intervenção brasileira no Haiti, que reproduziu a lógica de atuação das grandes potências e teria servido, na prática, como exercício de treinamento das Forças Armadas para o desempenho das funções de polícia e violações, especialmente no Rio de Janeiro. Contrariamente ao imperialismo americano, o PSOL propôs que o Brasil se posicionasse de forma clara contra os novos nacionalismos conservadores, em particular à política externa norte-americana de Trump, contra o militarismo. Propôs também um amplo movimento de retirada de bases militares norte-americanas no continente, e de oposição à possibilidade de presença da Quarta Frota no Atlântico Sul. De modo semelhante, o PDT manifestou trabalhar contra a instalação de bases militares de potências externas no continente sul-americano. Já o PPL e o PT destacaram a necessidade de fortalecer as relações Sul-Sul para a conquista de autonomia frente aos EUA, superando sua hegemonia.

Especificamente, o PDT salientou não tolerar a compra por estrangeiros de ativos que compõem ou apoiam nosso complexo industrial de defesa e propôs o desenvolvimento de agenda de reforma da ordem de segurança no mundo que constranja as grandes potências no uso unilateral da força armada. O PSOL criticou o discurso das "novas ameaças" promovido pelas principais potências por despolitizar agendas, que passam a ser tratadas na lógica da exceção e de quebras dos mecanismos democráticos. Ademais, o partido criticou as violências sofridas pelos palestinos e outros povos oprimidos.

\section{Sustentabilidade}

O conceito de sustentabilidade remonta ao estudo de Vernadsky (1986) sobre a biosfera. No âmbito das relações internacionais as discussões mais recentes a respeito da sustentabilidade estão ligadas aos Objetivos de Desenvolvimento do Milênio da ONU, estabelecidos em 2000 e em 2015. A 
temática da sustentabilidade foi presente nos manifestos de campanha do MDB, NOVO, PDT, PSDB, PSOL, PT e REDE. Com exceção do NOVO, que se limitou em seu manifesto a apontar o caráter global da sustentabilidade, os demais partidos apresentaram propostas relacionadas à temática e comprometeram-se com os objetivos assumidos no Acordo de Paris. PDT, PSDB e PT comprometeram-se também com os Objetivos do Desenvolvimento Sustentável (ODS). Os dois últimos destacaram ainda a necessidade de cooperação na gestão e valorização do bioma compartilhado da Amazônia.

Particularmente, o PT defendeu a criação de um Fundo de Adaptação dos países da América Latina e do Caribe para apoiar países da região a enfrentar desastres climáticos. Por sua vez, o PSOL focou-se em propostas para zerar o desmatamento, visando ao Brasil "cumprir as metas assumidas na COP 21 do clima e na COP 13 da biodiversidade" (2018: 132). O PDT apontou medidas visando a redução do desmatamento e da poluição. Finalmente, a REDE destacou a liderança do Brasil nas discussões internacionais sobre mudança do clima e biodiversidade e sugeriu que a competitividade internacional da agropecuária brasileira poderia ser aumentada caso o país avançasse nas questões socioambientais. Desse modo, a defesa da sustentabilidade estende-se da esquerda à centro-direita, não sendo associada à um espectro ideológico em específico.

\section{CONTINUIDADE OU MUDANÇA? AS VARIAÇÕES NOS POSICIONAMENTOS DOS PARTIDOS ENTRE AS ELEIÇÕES DE 2010 E 2018}

As três últimas eleições presidenciais no Brasil marcaram o apogeu e a queda do petismo. Em 2010, a alta aprovação do então Presidente Lula contribuiu decisivamente para a eleição de sua ministra da Casa Civil, Dilma Rousseff. Em contraste, a eleição de 2014 ocorreu em um contexto de aumento da polarização, cuja origem remonta às manifestações de junho de 2013. A reeleição da Presidenta Dilma com uma margem estreita de votos e a contestação do resultado por seu adversário, Aécio Neves, levaram a polarização a um novo patamar, que culminou no impeachment de 
Rousseff e na prisão de Lula. Foi neste contexto de profunda polarização que ocorreu a eleição de 2018.

Buscando compreender esse processo político mais amplo, questionamos neste trabalho se ocorreram mudanças significativas nos posicionamentos dos partidos que disputaram as eleições presidenciais brasileiras entre 2010 e 2018. A análise aqui empreendida mostra tanto tendências de continuidade, como a manutenção da ordem de posicionamento dos partidos que disputaram as últimas três eleições na escala esquerda-direita; quanto tendências de mudança, tais como movimentos de partidos mais à esquerda e mais à direita. Os dados completos podem ser observados no Gráfico III.

PSTU, PSOL, PT, DC e PSDB são os únicos partidos que encabeçaram chapa nas três últimas eleições presidenciais. Constata-se que, nesse período, os cinco partidos moveram-se mais à esquerda em 2018, sem alterar a ordem de posicionamento entre eles de uma eleição para outra.

Gráfico III. Posicionamento partidário na escala esquerda-direita em política externa nas eleições de 2010, 2014 e 2018
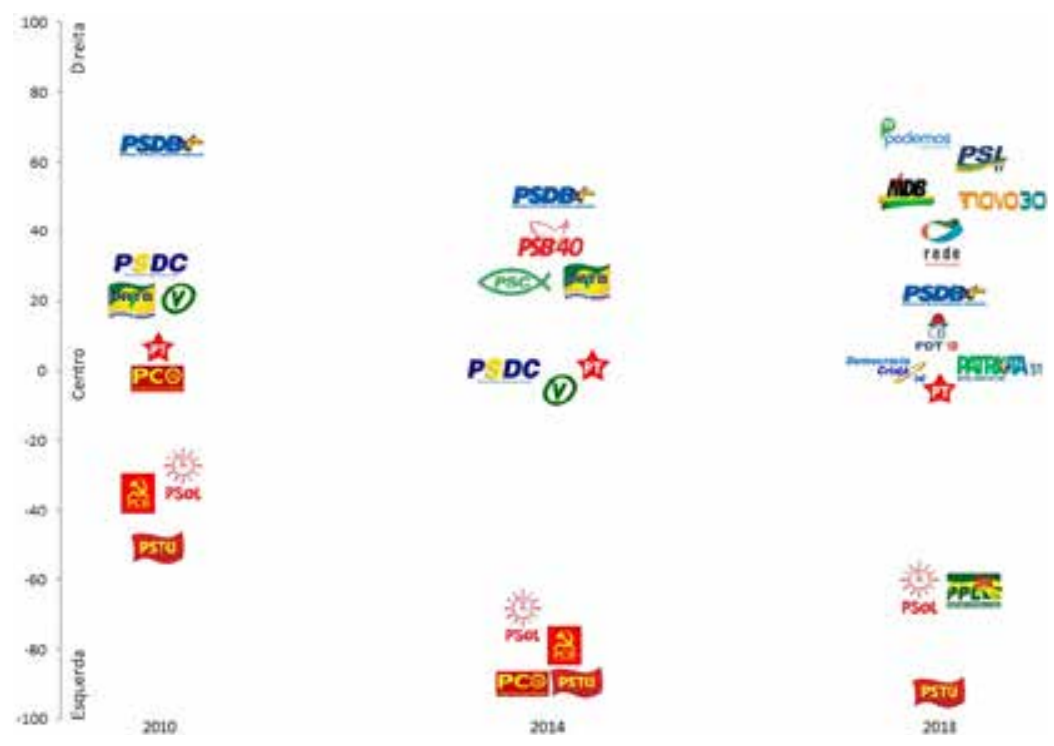

Fonte: Elaboração própria.
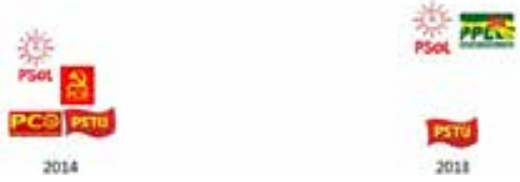

202 
Saindo por um momento do ponto de vista partidário, é possível compararmos os posicionamentos da candidatura de Marina Silva nas três eleições, cada uma delas disputada por um partido diferente. Em 2010, pelo PV, Marina se posicionou em "20" à centro-direita. Em 2014, no PSB, marcou "37,5". Em 2018, na REDE, marcou “43,1". Trata-se de uma variação que posiciona a candidatura de Marina Silva mais à direita na política externa, de eleição para eleição, em um sentido contrário aos posicionamentos daqueles cinco partidos. Nesse ponto, é interessante compararmos as estimações de Marina Silva com as do PSDB no período. Em 2010 e 2014, o PSDB estava à direita de Marina Silva. Em 2018, contudo, o PSDB ficou posicionado à esquerda da REDE. Desse modo, Marina Silva e PSDB seguiram tendências opostas. Enquanto o PSDB posicionou-se cada vez mais à esquerda, Marina Silva posicionou-se cada vez mais à direita na política externa nas eleições ocorridas entre 2010 e 2018.

Estando posicionado como o partido mais à direita nas eleições de 2010 e 2014, o PSDB foi apenas o sexto partido mais à direita nas eleições de 2018, ficando atrás de PODEMOS, PSL, MDB, NOVO e REDE. Essa tendência decorre do partido ter optado por manifestar posições mais centristas em 2018, em uma estratégia para se contrapor à polarização entre PT e PSL em 2018. Essa estratégia passou pela formação de uma ampla coligação eleitoral com partidos de centro-direita, o "centrão" (PP, PTB, PSD, SD, PRB, DEM, PPS e PR).

Como podemos observar no Gráfico III, há um maior número de partidos posicionados à direita no espectro ideológico que concorreram para a Presidência da República e que se aglutinaram mais fortemente nessa posição. Na onda do crescimento da extrema-direita, partidos como PODEMOS, PSL e NOVO, assim como o então partido no governo, MDB, posicionaram-se à direita em 2018. O PRTB que havia disputado as eleições de 2010 e 2014 como cabeça de chapa, encampou a candidatura à vice na chapa do PSL em 2018. Uma análise dos posicionamentos do partido mostra que ele foi movendo-se mais à direita, de uma eleição para outra, culminando com a aliança com o PSL. Nesse sentido, o PSC que disputou as eleições de 2014 também se moveu mais à direita em 2018, quando ocupou a candidatura à vice-presidência na chapa do PODEMOS. 
Em um sentido contrário, partidos que disputaram as eleições de 2010 e 2014, mas não disputaram como cabeça de chapa nas eleições de 2018, como PV, PCO e PCB, moveram-se mais à esquerda de uma eleição para a outra. Finalmente, cabe destacar as posições de partidos que disputam apenas uma eleição, como as de PSB e PDT, à centro-direita, em 2014 e 2018, respectivamente; O PATRIOTA ao centro e o PPL à esquerda nas eleições de 2018.

No que diz respeito à comparação dos posicionamentos partidários na escala minimalista-protagonista nas últimas três eleições presidenciais, conforme o Gráfico IV, podemos observar que os partidos geralmente classificados à esquerda e à extrema-esquerda são os que têm se posicionado no espectro minimalista da escala. Por outro lado, partidos de centro-esquerda, centro-direita, e direita têm se posicionado no espectro protagonista da escala. Em relação ao ordenamento dos partidos, de eleição para eleição, podemos observar que o PT manteve nas três

Gráfico IV. Posicionamento partidário na escala minimalista-protagonista nas eleições de 2010, 2014 e 2018

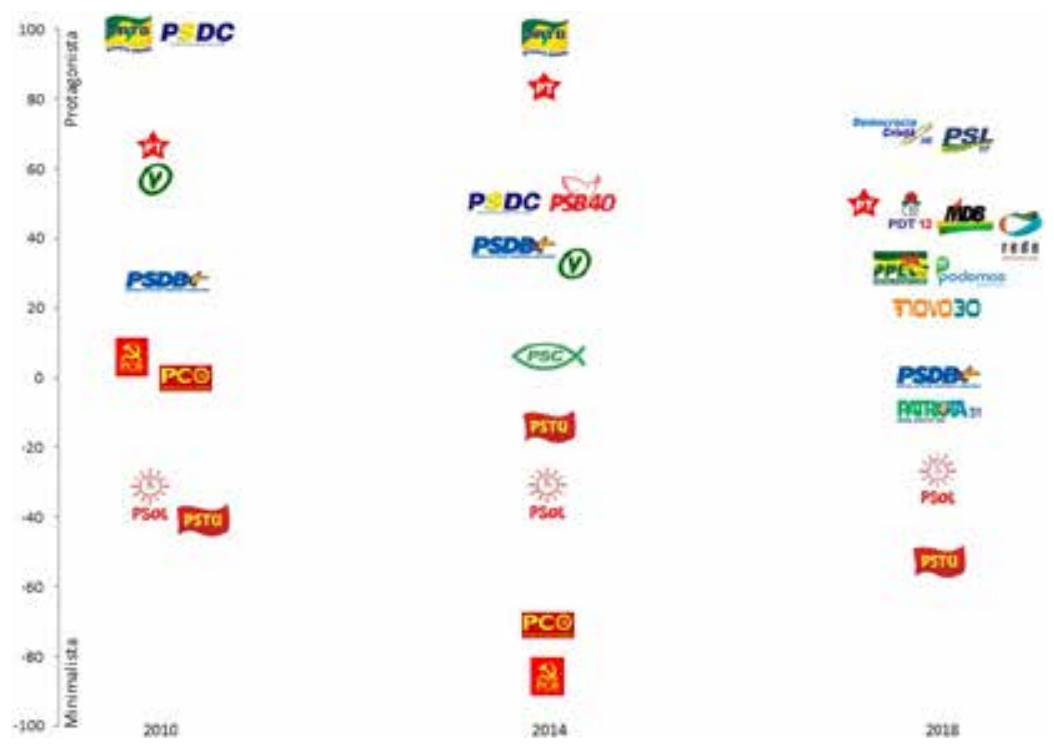

Fonte: Elaboração própria. 
eleições um posicionamento mais protagonista que o PSDB. Por outro lado, cabe destacar que nas três eleições consideradas ao menos um partido de direita posicionou-se no sentido mais protagonista que o PT. Trata-se de PRTB (2010 e 2014), DC (2010 e 2018) e PSL (2018). No lado minimalista do espectro, PSOL e PSTU, sempre próximos, alteraram a ordem de seus posicionamentos entre 2010 e 2018.

\section{CONCLUSÕES}

Caracterizada pela quebra da polarização entre PT e PSDB, a eleição presidencial brasileira de 2018 fora vencida por Jair Bolsonaro, então no PSL, em um movimento, mais amplo, de crescimento da direita e da defesa de seus ideários. Neste artigo, buscamos compreender parte deste processo tendo como foco a política externa, que embora não seja uma temática tipicamente decisiva para a escolha do eleitor, ganhou relevância durante o processo eleitoral. Desse modo, nosso objetivo foi estimar o posicionamento e diferenciar ideologicamente os partidos que disputaram as eleições presidenciais brasileiras de 2018.

Estimadas nas escalas esquerda-direita e minimalista-protagonista, as posições dos partidos em assuntos de política externa em 2018 foram contrastadas também com as posições partidárias estimadas nos manifestos das campanhas de 2010 e 2014 . Os resultados demonstraram que a maioria dos partidos que disputaram as eleições presidenciais de 2018 se posicionaram à direita na política externa, e que apenas os partidos posicionados à extrema-esquerda defenderam um papel minimalista para a política externa brasileira.

Ademais, observamos nas eleições de 2018 diferenças nos alinhamentos estratégicos internacionais prioritários dos partidos. Nesse sentido, dividimos os manifestos analisados em três grupos. No primeiro grupo encontram-se os partidos que manifestaram prioridade às relações Sul-Sul. Nesse grupo estão apenas partidos de esquerda: PSOL, PPL e PT. No segundo grupo encontram-se os partidos que apesar de enfatizarem as relações com o Sul, manifestaram a necessidade de fortalecimento das relações com países do Norte. Neste grupo estão PDT, REDE e mDB, partidos 
que orbitam da centro-esquerda à centro-direita. Finalmente, está alocado no terceiro grupo o PSL, partido que manifestou prioridade em estabelecer relações bilaterais vis-à-vis às multilaterais e elencou como parceiros prioritários somente países do Norte.

Ao comparar os manifestos partidários de 2018 com os das eleições de 2010 e 2014, verificamos que há estabilidade na ordenação ideológica dos partidos, da esquerda à direita. Há também maior aglutinação dos partidos no campo da direita quando comparado com à esquerda. Duas indicações podem ser feitas a respeito desse aspecto. Primeiro, é visível a institucionalização dos partidos políticos brasileiros e, para o eleitor médio, ficam mais claras as diferenças ideológicas entre eles. Segundo, o Brasil não pode ser excluído da crescente onda conservadora que ocorre no mundo e que encontra respaldo na polarização da sociedade, a qual contribuiu para uma maior concentração de posicionamento à direita dos partidos que disputaram as eleições presidenciais brasileiras de 2018.

Esse trabalho indica que a compreensão da política externa em processos eleitorais pode ser uma área frutífera de análise. Há muito o que explorar, tanto quantitativamente quanto qualitativamente. Ainda são necessários trabalhos que compreendam um recorte temporal mais significativo, procurando entender a relação entre as diferentes características do sistema político brasileiro e posicionamentos em política externa, assim como trabalhos que tratem qualitativamente dos discursos, seja em perspectiva comparada dentro do Brasil ou mesmo com outros países. Ademais, há espaço para pesquisas que se debrucem sobre a relação da polarização em política externa com eventos no cenário internacional e os efeitos nos regimes democráticos contemporâneos.

\section{REFERÊNCIAS BIBLIOGRÁFICAS}

Almeida, Paulo. "Partidos Políticos e Política Externa". Revista de Informação Legislativa 23.91 (1986): 173-216.

Almeida, Paulo. "A política externa nas campanhas presidenciais". Revista Espaço Acadêmico 6.62 (2006). 
ARES, CRISTINA y ANDREA VOLKENS. "¿Por qué y cómo se está extendiendo el Manifesto Project a América Latina?" Revista Española de Ciencia Política 43 (2017): 115-135.

Ascencio, Sergio y Bingham Powell. "Party System Polarization: Citizen Perception, Manifesto Statements, and Change". Paper Presented at the Annual Meeting of the Midwest Political Science Association. Chicago (2016).

BARDIn, LaURENCE. Análise de conteúdo. Lisboa: Edições 70, 2002.

Benoit, KenneT; Michael Laver; Will Lowe; Slava MikHaylov. "How to Scale Coded Text Units without Bias: A Response to Gemenis". Electoral Studies 31.3 (2012): 605-8.

Borges, ANDré E RoBerTo Vidigal. "Do lulismo ao antipetismo? Polarização, partidarismo e voto nas eleições presidenciais brasileiras". Opinião Pública 24.1 (2018): 53-89.

Braga, Maria Do Socorro e Jairo Pimentel Jr. "Os partidos políticos brasileiros realmente não importam?” Opinião Pública 17.2 (2011): 271-303. Buchanan, James y GORdon Tullock. The Calculus of Consent Logical Foundations of Constitutional Democracy. Ann Arbor: University of Michigan Press, 1965.

Contrera, Flávio e Matheus lucas Hebling. "Partidos políticos, ideologias e política externa nas eleições presidenciais brasileiras de 2014". Colombia International 90 (2017): 191-220.

Friedman, Milton. Capitalism and freedom. Chicago: University of Chicago Press, 1962.

Hastings, Adrian; Alistair Mason; Hugh PIPER. The Oxford Companion to Christian Thought. Oxford: Oxford University Press, 2000.

HayeK, Friedrich A. Von. The Road to Serfdom. Chicago: University of Chicago Press, 1944.

JERVIS, RoBerT. Perception and Misperception in International Politics.

Princeton: Princeton University Press, 1976.

Kant, Immanuel. To Perpetual Peace: a Philosopbical Sketch. Indianapolis: Hackett Publishing, 2003.

KEYNES, JOHN MAYNARD. The General Theory of Employment, Interest and Money. London: Palgrave Macmillan, 1936. 


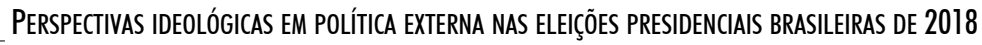

Kuingemann, Hans-Dieter; Andrea Volkens; Judith Bara; IAn Budge; MiCHAel MacDonald. Mapping Policy Preferences II: Estimates for Parties, Electors, and Governments in Eastern Europe, the European Union and the OECD, 1990-2003. Oxford: Oxford University Press, 2006. Koch, Michael T. e Patricia Suluivan. "Should I Stay or Should I Go: Partisanship, Approval and the Duration of Democratic Military Interventions". Journal of Politics 72.3 (2010): 616-29.

LENIn, VlaDimiR. Imperialism, the Highest Stage of Capitalism. London: Penguin Classics, 2010.

Limongi, Fernando e Rafael Cortez. "As Eleições de 2010 e o Quadro Partidário". Novos Estudos CEBRAP. 88 (2010): 21-37.

LIST, FRIEDRICH. The National System of Political Economy. London: Longmans, Green and Co, 1841.

LOPES, DAWISSON e CARLOS FARIA. "Eleições presidenciais e política externa brasileira". Estudos Internacionais 2.2 (2014): 139-148.

LuPu, NOAM. "Party Brands and Partisanship: Theory with Evidence from a Survey Experiment in Argentina". American Journal of Political Science 57.1 (2013): 49-64.

Maciel, Ana Paula Brito; Anderson De Oliveira Alarcon; Éder Rodrigo Gimenes. "Partidos políticos e espectro ideológico: parlamentares, especialistas, esquerda e direita no Brasil". Revista Eletrônica de Ciência Política 8.3 (2017): 72-88.

Madeira, Rafael e Gabriela Tarouco. "Esquerda e Direita no Brasil: uma análise conceitual". Revista Pos CSO. 8.15 (2011): 171-186.

Madeira, Rafael e Gabriela Tarouco. "Ideologia e partidos políticos no Brasil". Civitas 12.2 (2012): 205-208.

Melo, Carlos Ranulfo e Rafael CÂmara. "Estrutura da competição pela Presidência e consolidação do sistema partidário no Brasil". Dados 55.1 (2012): 71-117.

MerZ, NicolaS; Sven Regel; JiRKa LewANDOwski. "The Manifesto Corpus: A New Resource for Research on Political Parties and Quantitative Text Analysis". Research And Politics 3.2 (2016): 1-8.

Oliveira, AmÂNCiO e Janina OnukI. "Eleições, partidos políticos e política externa no Brasil”. Revista Política Hoje 19.1 (2010): 144-185. 
Rathbun, Brian C. Partisan Interventions: European Party Politics and Peace Enforcement in the Balkans. Ithaca: Cornell University Press, 2004.

Rathbun, Brian C. "Does One Right Make a Realist? Conservatism, Neoconservatism, and Isolationism in the Foreign Policy Ideology of American Elites". Political Science Quarterly 123.2 (2008): 271-99.

Regel, Sven. The Manifesto Project Database: A Large-scale Political Text Access and Analysis Database. Amsterdam, Netherlands, 2010.

Ribeiro, Ednaldo; Jan Carreirao; Julian Borba. "Sentimentos partidários e antipetismo: condicionantes e covariantes". Opinião Pública 22.3 (2016): 603-637.

RICARDO, DaVID. On the Principles of Political Economy and Taxation. London: John Murray, 1817.

Sartori, Giovanni. Parties and Party Systems: A Framework for Analysis. Cambridge: Cambridge University Press, 1976.

Silva, Dennisson; Willber Silva Nascimento; Anulfo Paranhos; Emerson Tiago Alves; Suzana Alves; Maria Augusta TeiXaira Oliveira. "Downs vence mais uma vez? Posicionamento ideológico-partidário nas eleições 2012". Revista Política Hoje 22.1 (2013): 206-49.

SMiTH, ADAM. An Inquiry into Nature and Causes of the Wealth of Nations. New York: A.M. Kelley, 1966.

TAROUCO, Gabriela e Rafael MadeIRA. "Esquerda e direita no sistema partidário brasileiro: análise de conteúdo de documentos programáticos". Revista Debates 7.2 (2013a): 93-114.

TAROUCO, Gabriela e RAFAel MadeIRA. "Partidos, programas e o debate sobre esquerda e direita no Brasil". Revista de Sociologia e Política 21.45 (2013b): 149-165.

TATAGiba, LuCiana. "1984, 1992 e 2013. Sobre ciclos de protestos e democracia no Brasil". Política e Sociedade 13.28 (2014): 35-62.

Telles, Helcimara. "A Direita Vai às Ruas: o antipetismo, a corrupção e democracia nos protestos antigoverno". Ponto e Vírgula 16 (2016): 97-125.

VERnADSKY, Vladimir. The Biosphere. Oracle, (Arizona): Synergetic Press, 1986. 


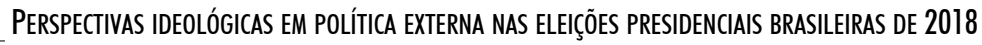

Volkens, Andrea; Cristina Ares; Radostina Bratanova; Lea Kaftan. "Análisis de contenido de textos con referencias al Manifesto Project (20002015): temas, actores, y métodos para medir preferencias políticas". RIPS: Revista De Investigaciones Políticas y Sociológicas 14.2 (2015): 233-238.

Volkens, Andrea; Judith Bara; IAn Budge; Michael D. MaCdonald; Hans-DieTer Kuingemann. Mapping Policy Preferences from Texts. Statistical Solutions for Manifesto Analysts. Oxford: Oxford University Press, 2013.

\section{DOCUMENTOS ANALISADOS}

DC. (2018). "Diretrizes Gerais de Governo para construir um novo e melhor Brasil". Manifesto disponível http://divulgacandcontas.tse.jus.br (consultado em 12 de novembro de 2018).

MDB. (2018). "Pacto pela confiança! Programa de Governo da Coligação 'Essa é a solução'”. Manifesto disponível http://divulgacandcontas.tse. jus.br (consultado em 12 de novembro de 2018).

NOVO. (2018). "Mais oportunidades, menos privilégios: programa de governo 2019/2022”. Manifesto disponível http://divulgacandcontas.tse. jus.br (consultado em 12 de novembro de 2018).

PATRIOTA. (2018). "Plano de nação para a Colônia Brasileira". Manifesto disponível http://divulgacandcontas.tse.jus.br (consultado em 12 de novembro de 2018).

PDT. (2018). "Diretrizes para uma estratégia nacional de desenvolvimento para o Brasil". Manifesto disponível http://divulgacandcontas.tse.jus.br (consultado em 12 de novembro de 2018).

PODEMOS. (2018). "Plano de Metas 19+1 pela refundação da República!" Manifesto disponível http://divulgacandcontas.tse.jus.br (consultado em 12 de novembro de 2018).

PPL. (2018). "Distribuir a renda, superar a crise e desenvolver o Brasil". Manifesto disponível http://divulgacandcontas.tse.jus.br (consultado em 12 de novembro de 2018). 
PSDB. (2018). "Diretrizes Gerais". Manifesto disponível http://divulgacandcontas.tse.jus.br (consultado em 12 de novembro de 2018).

PSDB. (2018b). Horário Gratuito de Propaganda Eleitoral. Programa disponível https://www.poder360.com.br/ (consultado em 15 de novembro de 2018).

PSL. (2018a). "O Caminho da prosperidade. Proposta de Plano de Governo". Manifesto disponível http://divulgacandcontas.tse.jus.br (consultado em 12 de novembro de 2018).

PSL. (2018b). Horário Gratuito de Propaganda Eleitoral. Programa disponível https://www.poder360.com.br/ (consultado em 15 de novembro de 2018).

PSOL. (2018). "Programa da Coligação Vamos sem medo de mudar o Brasil". Manifesto disponível http://divulgacandcontas.tse.jus.br (consultado em 12 de novembro de 2018).

PSTU. (2018). "16 pontos de um programa socialistas para o Brasil contra a crise capitalista". Manifesto disponível http://divulgacandcontas.tse. jus.br (consultado em 12 de novembro de 2018).

PT. (2018). "Plano de Governo 2019-2022". Manifesto disponível http://divulgacandcontas.tse.jus.br (consultado em 12 de novembro de 2018). REDE. (2018). "Brasil justo, ético, próspero e sustentável". Manifesto disponível http://divulgacandcontas.tse.jus.br (consultado em 12 de novembro de 2018). 